\title{
Quality of Postgraduate Research Supervision and Training: A Mixed-Method Student Perspective
}

\author{
*Petronella Jonck, PhD Psychology \\ ${ }^{*}$ Corresponding Author, B.Soc.Sc. Hons. Industrial Psychology, Deputy Director: Research and Innovation \\ The National School of Government, 70 Meinjies Street, Sunnyside, Pretoria, 0001
}

\author{
Eben Swanepoel (Masters Educational Psychology, UFS) \\ Faculty of Humanities: Teacher Education, Central University of Technology, Free State, Herlin 2 \\ David Botha, Heuwelsig, Bloemfontein, 9301; ebenswan@gmail.com
}

\section{Doi:10.5901/mjss.2016.v7n2p259}

\section{Abstract}

\begin{abstract}
The primary aim of the research reported on in this article was to pilot a measuring instrument to determine postgraduate students' perception of postgraduate supervision with specific reference to the research component thereof. The sample consisted out of 34 postgraduate students from various higher education institutions in South Africa subsuming masters-, doctoral students and postdoctoral fellows. The measuring instrument that was piloted was based on the G3S-SP scale that measure health sciences graduate students' perception of quality of supervision. The abridged version used in this study included an introductory section as well as open-ended questions. Statistical analysis indicated that the three subscales as well as the total scale have a Cronbach Alpha coefficient of 0.94. Factor analysis revealed a five-factor structure accounting for $76.42 \%$ of the variance. Pearson's-product moment correlation indicated that all the aspects measured had moderate to strong correlations with each other. It is recommended that the study be used as a basis for further investigation.
\end{abstract}

Keywords: Postgraduate supervision; postgraduate student; supervisor; liberal discourse; post-liberal theoretical framework

\section{Introduction}

Internationally there is increasing pressure on higher education institutions with regard to the quality of postgraduate supervision, especially in light of intensifying accountability (Lee \& McKenzie, 2011). Moreover, funding for higher education institutions in many countries, as is the case in South Africa, is directly linked to the completion rate of postgraduate students (De Beer \& Mason, 2009). Institutions of higher education locally are called upon to increase access and throughput in postgraduate programmes in order to improve the research skills of human capital flow and to increase research-based knowledge (Botha, 2010). In a document published by the Department of Science and Technology it was indicated that in 2010 fifty-eight thousand three hundred postgraduate students enrolled, while only 10 070 graduated. South Africa produces plus minus $30 \mathrm{PhD}$ graduates per million per annum with a completion rate of $12.24 \%$, in comparison 100 to $250 \mathrm{PhD}$ graduates produced by most developed and emerging economies. The overall completion rate for postgraduate students was 17.27\% in 2010 (South African Research and Innovation Management Association, July 2013).

Literature contends that postgraduate supervision is one of the most crucial determinants of student outcomes (Brew \& Peseta, 2004). Research conducted by Lee and McKenzie (2011), as well as Pearson and Brew (2002), indicated a critical relationship between the quality of postgraduate supervision and the aforementioned. Postgraduate supervision constitutes both a knowledge and relational process, which takes place during encounters between students and supervisors. Within this learning process enfolds the direct objective of postgraduate supervision, which is to yield independent researchers by furnishing them with the appropriate knowledge, skills and attributes (Franke \& Arvidsson, 2011). Botha (2010), drawing on the work of Jansen, Herman and Pillay (2004) asserted that effective supervision should involve research learning, which subsumes knowledge to complete a research project together with the emotional, social, political and cognitive understanding that constitute such learning.

While postgraduate supervision might be well researched in the context of "effective supervision" (Petersen, 2007), the question remains how students can provide insight into their personal postgraduate experiences (Lee \& McKenzie, 2011). Against this background the primary objective of the study was to pilot a measuring instrument to determine how 
postgraduate students perceive postgraduate supervision with specific reference to the research component of the before mentioned. The secondary objectives included amongst other the following research questions:

- Do the independent variables age, gender, field of study, year of enrolment and academic qualification statistically significantly influence the dependent variable as determined by four factors?

- Is there a statistically significant relationship between perceived preparedness of the candidate with reference to the research component of their studies, their expectations, supervisory involvement and the interpersonal relationship with the research supervisor?

- What variance in the interpersonal relationship between the research supervisor and candidate can be attributed to the preparedness of the candidate, in addition to their expectations, and the involvement of the supervisor?

Furthermore, the study aimed to provide a rich picture of how research candidates perceive the research supervisory relationship.

\section{Theoretical Framework}

The expectations of postgraduate students are increasing, concurrently the demand to finish the expected manuscript in a timely fashion is placed along the need to produce output of high quality that meet the required expectations (Lee, 2007). Previous research indicated that the framework or approach on part of the supervisor highly influence the process through which the output is obtained. A hands-on approach reflects a method on part of the supervisor that subsumes a mutual understanding and agreement between the candidate and supervisor, and in turn has also been shown to increase output in minimum time. As such, hands-on supervision refers to a teaching style based on regular supervisory intervention (Sinclair, 2004). It is further elaborated on that a hands-off approach to supervision leads to a more independent candidate and that the work is often seen of higher quality due to the knowledge of the candidate using their own primary resources with less aid from the supervisor. It is ultimately the expectation and experience of the supervisor that affect the quality and quantity of the output on part of the candidate and the manner in which this is attained (Lee, 2007). The framework within which the supervisor places their expectations during the supervision process must thus contribute to the holistic academic advantage of the candidate while the supervisor must consciously be aware of their supervisory theoretical underpinning.

According to Petersen (2007) postgraduate supervision is an under-theorised field despite being of considerable significance with regard to the postgraduate research agenda in recent years. Firth and Martens (2008) distinguished between liberal and post-liberal theoretical discourses. The last mentioned draws on the insights of feminism, postcolonialism and postmodernism rejecting the notion that autonomy and rationality should be central characteristics and goals of postgraduate supervision. On the other end of the continuum liberal discourses are perceived as driven by administrative and instrumental logic concerned with quality on a measurable level such as graduation rates (Manathunga, 2005). Maxwell and Smyth (2010) re-conceptualised postgraduate supervision to subsume three interrelated areas namely learning and teaching, student development and producing the outcome (thesis/dissertation) as a social practice. This re-conceptualisation is used as a theoretical base for the research management matrix. For the purpose of this paper the aforementioned paradigm by Maxwell and Smyth (2010) will be utilized.

\section{Methodology}

\subsection{Participants}

A total of 34 postgraduate students $(n=34)$ from various higher education institutions in South Africa were included in the pilot study. The sample consisted out of masters, doctoral and postdoctoral students. The biographical data of the respondent will be discussed sequentially. 
Table 1: Profile of the respondents $(n=34)$

\begin{tabular}{|c|c|c|c|c|}
\hline Variable & Level of measurement & $\mathrm{N}$ & $\%$ & Cumulative \% \\
\hline \multirow[t]{3}{*}{ Qualification } & Postdoctoral fellow & 4 & 11.76 & 11.76 \\
\hline & Doctoral student & 14 & 41.18 & 52.94 \\
\hline & Master's student & 16 & 47.06 & 100 \\
\hline \multirow{4}{*}{ 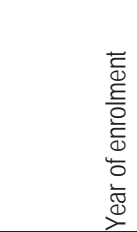 } & First year & 14 & 41.18 & 41.18 \\
\hline & Second year & 8 & 23.53 & 64.71 \\
\hline & Third year & 5 & 14.71 & 79.41 \\
\hline & Fourth year & 7 & 20.56 & 100 \\
\hline \multirow{2}{*}{ Gender } & Female & 24 & 70.59 & 70.59 \\
\hline & Male & 10 & 29.41 & 100 \\
\hline \multirow[b]{4}{*}{ 要 } & $20-24$ years & 2 & 5.88 & 5.88 \\
\hline & $25-29$ years & 5 & 14.71 & 20.59 \\
\hline & $30-34$ years & 9 & 26.47 & 47.06 \\
\hline & $35+$ years & 18 & 52.94 & 100 \\
\hline \multirow{7}{*}{ 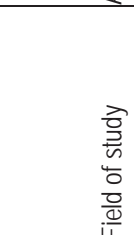 } & Education & 11 & 32.35 & 32.35 \\
\hline & English & 1 & 2.94 & 35.29 \\
\hline & Health & 10 & 29.41 & 64.71 \\
\hline & Humanities & 3 & 8.82 & 73.53 \\
\hline & IT & 1 & 2.94 & 76.47 \\
\hline & Law & 1 & 2.94 & 79.41 \\
\hline & Management Sciences & 7 & 20.59 & 100 \\
\hline
\end{tabular}

A total of 34 questionnaires were returned as can be seen from Table 1, of this number 4 students were postdoctoral fellows (11.76\%), 14 respondents were in the process of completing their doctoral studies (41.18\%), while the majority were doing their master's degree (47.06\%). The sample represents the population with a larger amount of master's students and declining number of postdoctoral fellows. Most of the respondents were in their first year of enrolment $(n=$ 14; $41.18 \%)$, followed by 8 respondents (23.53\%) in their second year, $5(20.56 \%)$ and $7(20.59 \%)$ students were respectively in their third and fourth year. The gender distribution was skewed towards female students with $24(70.59 \%)$ female and $10(29.41 \%)$ male students. As can be expected the majority were in the 35 and older age group $(n=18$; $52.94 \%)$, followed sequentially by the other age groupings. Diverse study field were included in the sample including education $(n=11 ; 32.35 \%)$, health $(n=10 ; 29.41 \%)$, management sciences $(n=7 ; 20.59 \%)$, humanities $(n=3 ; 8.82 \%)$, English, information technology and law $(n=1 ; 2.94 \%$ each).

\subsection{Research design}

A mixed method research design was used which can be defined as 'the collection or analysis of both quantitative and qualitative data in a single study' by means of collecting data concurrently or sequentially and 'involve the integration of the data at one or more stages' during the research process (Wagner, Kawulich \& Garner, 2012: 162). Quantitative data was gathered by means of the administering of a questionnaire, while qualitative data was elicited with rich picturing. Seeing is both a literal, biophysical process and a metaphor for conceptualization. As such it represents a bridge between materials and ideas as well as between theory and practice. By drawing images an individual can define, describe and portray objects of social inquiry and the relationship between them (Wagner, 2006). A characteristic of the research design is that it was an Ex Post Facto design. In non-experimental research the independent variables are not manipulated to examine their influence on the dependent variable.

\subsection{Data gathering}

The data collection instrument and consent form were posted on survey monkey and distributed to respondents. Rich 
picturing was done on the premise of physical artefacts produced by respondents that are open to interpretation. Respondents were asked to illustrate their postgraduate experiences and challenges as a process during focus group discussions. Snowball sampling was used to generate both the quantitative and qualitative sample. The qualitative sample represents a subset of the quantitative sample. Respondents were provided the questionnaire and asked to refer someone they know and they in turn completed the questionnaire and were asked to further refer prospective candidates. The aim of the study was to validate a measuring instrument, and for that reason non-random sampling was sufficient with snowball sampling being appropriate.

\subsection{Data collection instrument}

The data collection instrument is based on the G3S-SP, a scale measuring health sciences postgraduate students' perception of the quality of their supervision (Bravo, Saint-Mleux \& Dubois, 2007). The measuring instrument was adjusted to include a biographical section as well as open-ended questions and extended to be applicable on diverse study fields. An introductory section was added that was in the unabridged version included in the biographical section. Factor analysis of the unabridged G3S-SP indicated a two-factor structure accounting for $84 \%$ of the variance. The first factor $(\alpha=0.88)$ measured supervisors' involvement in the project design process. The second factor $(\alpha=0.76)$ looked at the student-supervisor relationship (Bravo et al., 2007).

The questionnaire piloted in this study consisted out of 3 sections. The first section covered the biographical data of the students where they had to provide information in line with their age, gender, and qualification registered for. Section B of the Questionnaire consisted of a Likert scale, where 1 was coded as completely agree to 4 reflecting completely disagree. This section covered information related to introductory statements (e.g. I am adequately prepared for graduate studies), supervisor involvement (e.g. My supervisor helped me structure the steps in my research), and interpersonal relations (e.g. I have a good professional relations with my supervisor). Section C covered qualitative data where students provided responses to open-ended questions such as: 'What do you consider to be stumbling blocks with regard to post graduate supervision?' With reference to the qualitative responses, candidates were also asked to draw a picture to represent their interaction with their supervisor.

\subsection{Data analysis}

Cronbach alpha coefficient was determined to measure the reliability of the measuring instrument. Followed by factor analysis, Kaiser-Meyer Olkin measure of sample adequacy as well as Bartlett's Test for Sphericity. Lastly, exploratory factor analysis was performed to investigate the validity of the measuring instrument. Descriptive analysis was achieved utilizing frequencies, percentages, cumulative frequencies, median, mean and standard deviation. In order to determine the influence of the independent variables on the dependent variable multivariate analysis of variance were performed. Pearson product-moment correlation and multiple regression analysis followed. Qualitative data analysis was done by means of phenomenography at which time a list of codes were developed and themes were identified.

\subsection{Ensuring trustworthiness of data}

Trustworthiness of the data was assured by means of both data and researcher triangulation. Representativeness checks where an artefact is reviewed to assess its representativeness as compared to other similar artefacts were also taken into consideration. In order to ensure a more trustworthy output, quantitative data was cross-examined with qualitative data from the same questionnaire referring to data triangulation. While, researcher triangulation also further ensures trustworthiness. As such, two researches were used to interpret the pictures. Furthermore, respondents were asked to validate the interpretation where possible.

\subsection{Ethical considerations}

Two ethical guidelines took precedence namely the protection of participants from physical and psychological harm and informed consent that were incorporated by means of a letter of consent that had to be signed by each respondent. The letter of consent specified that participation was voluntary. Participants were assured of anonymity and associated confidentiality. Respondents were also informed of the aim, purpose and outcome of the research project. 


\section{Results}

The primary objective of the research reported on in this paper was to pilot a measuring instrument aimed at determining postgraduate students' perception of received supervision to ensure its psychometric stability. Secondary objectives included determining the relationship between the different aspects of the measuring instrument amongst other. Against this background Table 2 provides the Cronbach Alpha coefficient results for the different sections of the questionnaire.

Table 2: Reliability of the measuring instrument

\begin{tabular}{|l|c|c|}
\hline Scale & Item & Cronbach Alpha \\
\hline Preparedness and expectations & 4 & 0.94 \\
\hline Supervisory involvement in project & 9 & 0.94 \\
\hline Interpersonal relationship & 8 & 0.94 \\
\hline Total scale & 21 & 0.94 \\
\hline
\end{tabular}

As can be seen from Table 2, the subdivisions of the questionnaire as well as the total scale have an alpha coefficient of 0.94 indicating that the measuring instrument is psychometrically stable and reliable. Factor analysis to determine the construct validity of the measuring instrument was conducted on 21 Likert scale items. An examination of the KaiserMeyer Olkin measure of sampling adequacy suggested that the sample was factorable (KMO $=0.69)$ and the Bartlett's Test for sphericity reached statistical significance, supporting the factorability of the correlation matrix. The results of an oblique rotation are depicted in Table 3 overleaf.

Table 3: Obliquely rotated component loading for the 21 survey items

\begin{tabular}{|l|c|c|c|c|c|}
\hline Component & $\mathbf{1}$ & $\mathbf{2}$ & $\mathbf{3}$ & $\mathbf{4}$ & $\mathbf{5}$ \\
\hline Communicating dissatisfaction & 0.829 & & & & \\
\hline Comfort with research environment & 0.823 & & & & \\
\hline Student-supervisor collaboration & 0.820 & & & & \\
\hline Students' expectation & 0.812 & & & & \\
\hline Professional relationship & 0.809 & & & -0.339 & \\
\hline Networking opportunities & 0.771 & & & 0.313 & \\
\hline Interpersonal relationship & 0.766 & & -0.322 & -0.322 & \\
\hline Supervisors attitude & 0.739 & & & & \\
\hline Subject knowledge of supervisor & 0.731 & & & & -0.415 \\
\hline Supervisors availability & 0.709 & & & & 0.621 \\
\hline Provision of feedback & 0.701 & & -0.371 & & \\
\hline Supervisory guidance & 0.685 & & 0.434 & & \\
\hline Material resources & 0.685 & & -0.349 & 0.369 & -0.301 \\
\hline Financial resources & 0.673 & -0.363 & -0.303 & 0.355 & \\
\hline Supervisors' expectations & 0.650 & 0.481 & 0.303 & & \\
\hline Supervisory involvement & 0.638 & -0.573 & & & \\
\hline Institutional process in case of disagreement & 0.594 & & & & \\
\hline Advantage of feedback & 0.586 & -0.379 & 0.467 & & \\
\hline Structure provided by the supervisor & 0.441 & 0.715 & 0.302 & & \\
\hline Student's expectation of the program & 0.474 & -0.642 & 0.422 & & \\
\hline Preparedness & & 0.470 & 0.455 & 0.586 & \\
\hline Eigen-values & $\mathbf{9 . 9 7 5}$ & $\mathbf{2 . 1 8 5}$ & 1.610 & $\mathbf{1 . 2 1 3}$ & $\mathbf{1 . 0 6 2}$ \\
\hline Percentage of total variances & $\mathbf{4 7 . 5 0}$ & $\mathbf{1 0 . 4 1}$ & $\mathbf{7 . 6 7}$ & $\mathbf{5 . 7 8}$ & $\mathbf{5 . 0 6}$ \\
\hline
\end{tabular}

When loadings less that 0.30 were excluded, the analysis yielded a five-factor solution. Factor one which reported the highest percentage of the total variance $(47.50 \%)$ loads onto all the aspects measured with the exclusion of preparedness. Seven items load onto the second factor related to learning and teaching such as the provision of information concerning financial resources, structure, feedback, the supervisors' expectation as well as the students' expectations of the program he or she is enrolled in. Factor three loads onto similar aspects with the addition of speed with which feedback is provided, supervisory guidance and preparedness of the student. Items for factor four related to 
student development more specifically the professional relationship, provision of networking opportunities, interpersonal relationship, material and financial assistance as well as preparedness. Items for Factor 5 identified subject knowledge of the supervisor, the availability of supervisor as well as material resources. Factor structures resemble the four subscales listed in the questionnaire as well as the three inter-related areas suggested by Maxwell and Smyth (2010) with the addition of an overall factor and consequently support the construct validity of the questionnaire. The measures of central tendency will be summarised in Table 4 below.

Table 4: Measures for central tendency for the four aspects measured

\begin{tabular}{|l|c|c|c|c|c|}
\hline Variable & Median & Lower quartile & Upper quartile & $\bar{x}$ & Std \\
\hline Preparedness & 2.00 & 1.00 & 3.00 & 2.088 & 0.645 \\
\hline Expectations & 1.50 & 1.00 & 3.00 & 1.677 & 0.589 \\
\hline Supervisory involvement & 1.722 & 1.00 & 2.89 & 1.739 & 0.568 \\
\hline Interpersonal relations & 1.625 & 1.00 & 3.25 & 1.805 & 0.662 \\
\hline
\end{tabular}

According to Table 4 postgraduate students indicated a moderate to very positive cognitive perception of the postgraduate supervision they received. The aspect that received the most negative evaluation was preparedness. This was followed by interpersonal relationship, supervisory involvement and lastly expectations.

Multivariate analysis of variance was performed to determine the influence of the independent variables (gender, age to mention a few) on the dependent variable consisting of four factors measures by means of the questionnaire. Only field of study yielded a statistically significant influence on the combined dependent variable ( $f=3.16 ; p=0.012$; Roy's largest root $=0.646$; partial eta squared $=0.393$ ). When the results for the dependent variable were considered separately the only statistical significant influence were for supervisory involvement in the project as well as interpersonal relationship both on the $95^{\text {th }}$ percentile.

In order to examine the postgraduate supervision relationship further Pearson's product-moment correlation as well as multiple regression analysis were performed and illustrated in Table 5 and 6 below.

Table 5: Pearson's product-moment correlation results indicating the relationship amongst aspects measured

\begin{tabular}{|c|c|c|c|c|}
\hline & Preparedness & Expectations & Supervisory involvement & Interpersonal relationship \\
\hline Preparedness & 1 & & & \\
\hline Expectations & $\begin{array}{c}0.616 \\
0.000^{* *}\end{array}$ & 1 & & \\
\hline Supervisory involvement & $\begin{array}{c}0.483 \\
0.004^{\star \star}\end{array}$ & $\begin{array}{c}0.605 \\
0.000^{* *}\end{array}$ & 1 & \\
\hline Interpersonal relationship & $\begin{array}{l}0.436 \\
0.01^{\star \star}\end{array}$ & $\begin{array}{c}0.649 \\
0.000^{\star *}\end{array}$ & $\begin{array}{c}0.843 \\
0.000^{* *}\end{array}$ & 1 \\
\hline
\end{tabular}

${ }^{* *} p \leq 0.01$

The results showed that each of the four variables measured was statistically related to perceived postgraduate supervision. Results reveal a moderate relationship between supervisory involvement and preparedness $(r=0.483 ; p \leq$ $0.01)$, as well as interpersonal relationship and preparedness $(r=0.436 ; p \leq 0.01)$. A strong relationship were indicated for expectations with preparedness $(r=0.616 ; p \leq 0.01)$, supervisory involvement $(r=0.605 ; p \leq 0.01)$, as well as interpersonal relationship $(r=0.649 ; p \leq 0.01)$. Supervisory involvement and interpersonal relationship revealed a very strong correlation $(r=0.843 ; p \leq 0.01)$.

The hypothesis that preparedness, expectations and supervisory involvement statistically significantly predict the variance with regard to the interpersonal relationship between the candidate and supervisor was tested using multiple regression analysis. Table 6 display results of the aforementioned. 
Table 6: Multiple regression analysis with interpersonal relationship as dependent variable and the three remaining variables as independent variables

\begin{tabular}{|l|c|c|}
\hline \multirow{2}{*}{ Variables } & \multicolumn{2}{|c|}{ Interpersonal relationship } \\
\cline { 2 - 3 } & $\boldsymbol{\beta}$ & $\mathbf{P}$ \\
\hline Preparedness & -0.70 & 0.559 \\
\hline Expectations & 0.255 & 0.061 \\
\hline Supervisory involvement & 0.723 & $0.000^{* \star}$ \\
\hline $\mathrm{R}^{2}$ adjusted & \multicolumn{2}{|c|}{0.719} \\
\hline $\mathrm{R}^{2}$ & \multicolumn{2}{|c|}{0.744} \\
\hline F change & \multicolumn{2}{|c|}{29.099} \\
\hline Significant F change & \multicolumn{2}{|c|}{$000^{* *}$} \\
\hline
\end{tabular}

Results according to Table 6 , revealed that the largest portion of the variance in the interpersonal supervisory relationship can be attributed to the involvement of the supervisor in the research project $(\beta=0.723)$, accounting for $72.3 \%$ of the variance in the interpersonal relationship. This suggests that the more involved the supervisor appears to be the better the interpersonal relationship between the candidate and his/her postgraduate supervisor would be. The Beta value for expectations secondarily contributes to the interpersonal relationship $(\beta=0.255)$. Expectations accounts for $25.5 \%$ change in the variance of the dependent variable. According to this candidates who have clear expectations demonstrate a more favourable stance towards the postgraduate supervision process. Despite the latter only supervisory involvement statistically significantly predicted the interpersonal relationship between the supervisor and candidate. In terms of joint contribution of all the factors, Table 6 indicated that preparedness, expectations and supervisory involvement contributed in collaboration to the supervisory interpersonal relationship with a $R$ square value of $0.719(F=29.099 ; p \leq 0.000)$. Note that the adjusted $R^{2}$ value was used ascribed to the relative small sample size. This calculation indicated that the majority of the variance in the supervisory interpersonal relationship (72\%), was explained by the three predictor variables. Only $28 \%$ of the variance in the interpersonal supervisory relationship can be attributed to extraneous variables.

A total of 33 questionnaires with qualitative responses to three open-ended questions were captured. In the first question postgraduate students were asked to describe their postgraduate supervision experience. A total of 30 students responded with answers ranging from wonderful, satisfactory, and challenging to complete disillusionment. Students' responses were coded according to two streams, namely positive and negative responses respectively. An extract from a student typical of each code included: "Most satisfactory. My supervisor is very understanding and encouraging but does not impose his ideas on me at all, which suits my personality and aspirations for my studies perfectly." $(\mathrm{n}=18 ; 60 \%)$ and "Discouraging. My supervisor's attitude seems like I take last priority on her list." $(n=12 ; 40 \%)$. Note that when asked to describe postgraduate supervision most responses seem to be affective in nature.

When asked to identify stumbling blocks the following responses were elicited. The biggest stumbling blocks were time constraints and work load followed by delay in feedback and communication as well as lack of clear guidelines. Supervisors' attitude subsuming not being a priority, pessimism from supervisor and negative criticism were identified thirdly as a stumbling block. Institutional bureaucracy and not enough autonomy to work independently were mentioned fourthly followed by lack of financial support and availability. Extracts from typical student responses included:

"Time - as a part time student, working full time as a lecturer, obtaining time to complete tasks for my thesis within a deadline and meeting with my supervisor was sometimes a challenge." As well as: "Having to work in isolation without proper support structures certainly is the biggest stumbling block." With reference to the supervisory relationship the following were identified: "Stumbling blocks would be supervisors who are not available, do not offer constructive support and 'force' you to follow their argument."

Further probing revealed that the following coping mechanisms were used by postgraduate students in response to the aforementioned stumbling blocks: The majority respondents identified communication as the most important coping mechanism coupled with acceptance of the 'difficulty'. To seek information from other sources other than the supervisor were also utilized in addition to finding 'other' role models as possible mentors (for example peers, colleagues, field experts). Extracts from student typical responses include: "Support/motivation from those around me; working hard to complete tasks before deadlines; keeping the end goal in mind; using others as role models (those who have the same

${ }^{1}$ All quotes from respondents were used as is, no changes have been made to punctuation or language. 
qualification already)" and "I'll discuss it with my supervisor and together we will solve problems and challenges." Examples of adverse coping mechanisms used include: "Try to adjust my attitude towards my supervisor" indicative of avoidance.

The results of the rich picturing are presented in the following section. Each respondent were asked to draw a picture that symbolises their postgraduate supervision experience. It is important to understand that examples of experiences that are contrary to cases that support postgraduate supervision are illustrated to identify new dimensions and provide further insight.

\section{Respondent 1}

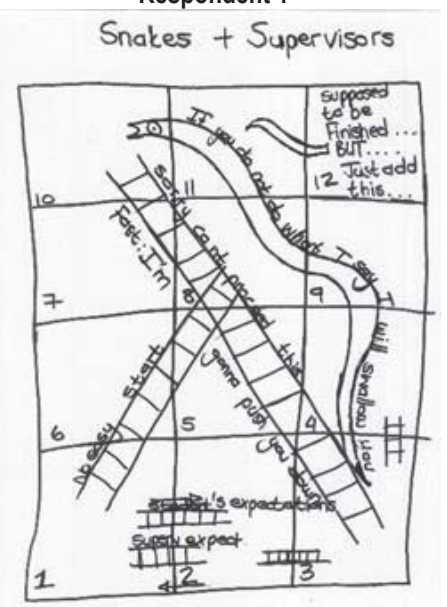

The first respondent viewed postgraduate supervision as a game of snakes and ladders where the supervisor is the snake that is a foe of the student. It is also evident from the drawing that the perceived expectations from the different parties opposes each other. Momentum is also apparent where the student feels that the supervisor is purposefully decreasing momentum. The student perceives their expetations to be moving in the oposite direction of the expectations of the supervisor, feeling restraint and also that whenever the end is in sight there is another obstacle to overcome that causes a setback within the logistics and movement of the process of obtaining the degree.

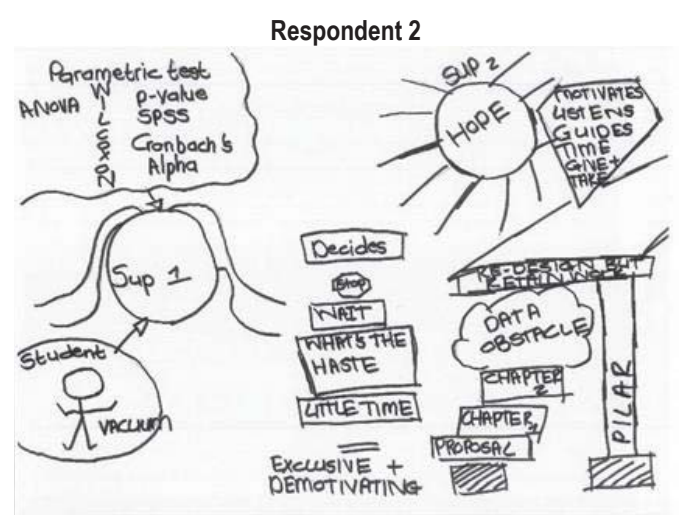

The second respondent made mention of two seperate supervisors. Under the leadership of the first supervisor the student experienced what he or she refers to as a vacuum. From the drawing it would seem the vacuum is related to the statistical aspect of the postgraduate supervision. Similar to the first respondent the time aspect is mentioned again. The whole experienced left the student feeling excluded and demotivated. The second supervisor represented a ray of light ascribed to enhanced emotional support provided including motivation, acknowledgement, reciprocity and such. It would 
seem the research structure is perceived as not firmly founded in the face of hope.

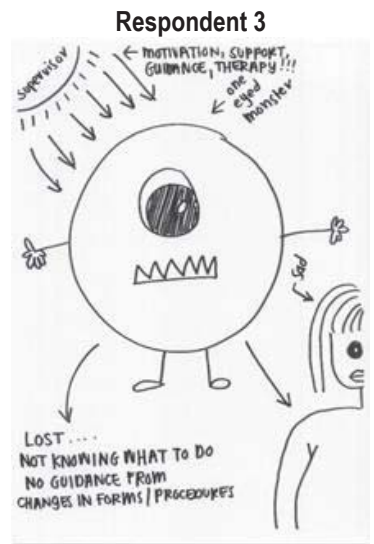

Respondent 3 described postgradute studies as their one eyed monster causing a great deal of sadness and negative emotions. This is due to being lost, not knowing what to do at times, changes in instituational beuracracy and lack of guidance. Similar to respondent 2 the supervisor is represented as a ray of light due to the provision of emotional support. With this, the respondent indicates that the supervisor plays a mediating role within finding direction and gaining understanding, and in turn perceives the role of the supervisor as essential to the framework of formations and procedures.

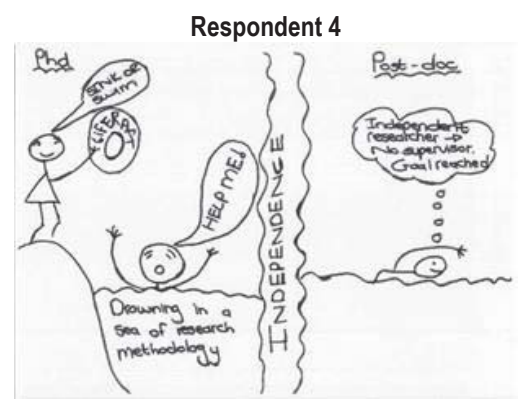

Respondent 4 has undergone all the stages in the postgraduate supervision process up untill postdoctoral fellowship and understood that even when it felt like he or she was drowning the goal was to yield independent researchers by furnishing them with the appropriate knowledge, skills and attributes. At the end of the process the student was able to work independently. This respondent indicates that even though their supervisor during $\mathrm{PhD}$ did not seem to be providing a base of support, the skills acquired is needed now during the post-doctorate fellowship and thus the method had a positive effect.

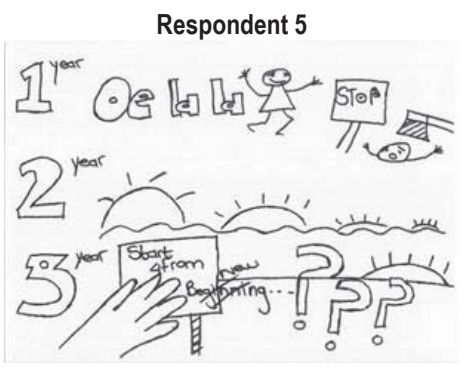


Respondent 5 started on an emotional high which ended in feeling decapitated at the end of the first year. In the second year the sun went done on his or her studies. In the third year they started anew and are unsure as to their feelings about their postgraduate studies and supervision. Note how postgraduate supervision is illustrated primarily in terms of an emotional experience. Two prominent parts of the picture is the sun and the goal milestone. By the end of the third year of supervision the student feels not only emotionally drained, but also negative that the process may become a cycle as the goal now needs to be completely changed.

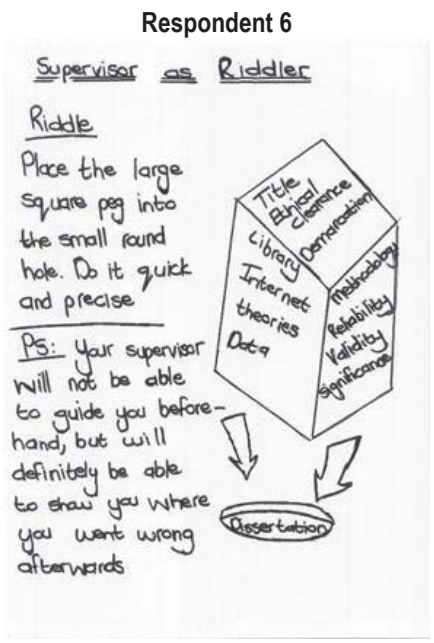

Respondent 6 perceived their supervisor as a riddler having impossible expectations and being unable or unwilling to assist the student. The supervisory relationship is characterised by negative feedback and criticism. The end product of the postgraduate studies is the round hole, while the research process is perceived as the square peg. The process once again forms an impediment to the student, while the student expexts the supervisor to aid and provide guidance to what is seemingly impossible.

Interesting to note is that in most of the pictures postgraduate studies are seen in some way as representing pending danger either by means of a snake, drowning, decapitation or a one eyed monster. When the supervisor provides emotional support and motivation it is represented as a sun while on the other hand there appear to be antagonistic feelings toward postgraduate supervision for example unwillingness to assist, demotivation and exclusion. It would appear that despite positive cognitive perception of postgraduate supervision, postgraduate supervision is interpreted affectively. From the rich pictures it can be concluded that emotional support and motivation plays a crusual role in postgraduate supervision.

\section{Findings and Discussion}

Statistical analysis indicated that the measuring instrument used to determine postgraduate students' perception of postgraduate supervision is psychometrically stable. The research confirms the results obtained by Bravo et al. (2007) and supports the assumption that despite its usefulness a qualitative approach could prove more effective in identifying conflict situations for example utilizing rich picturing. Furthermore postgraduate students indicated overall satisfaction with postgraduate supervision. The aspect that students were most satisfied with was the professional relationship that they have with their supervisor(s), while indicating a lack of knowledge as to the procedures to follow in the event of a disagreement with supervisor(s). The two aspects that students indicated as most unsatisfactory were the material resources to which they have access to, as well as the information supervisor(s) gave about financial resources. Multiple regression analysis indicated that the supervisory relationship is influenced to a large degree by how involved the supervisor seems to be. Time constraints and work load were identified as the biggest challenges postgraduate students face. Other challenges that were identified included not enough freedom to work independently, supervisor availability and commitment, overly pessimistic attitude of supervisor(s), and diverse aspects pertaining to feedback. Strategies employed by postgraduate students to overcome challenges, were communication, to find information elsewhere, and 
adjusting their attitudes. Qualitative analysis that was done using rich picturing indicated that emotional support from supervisor(s) plays a crucial role in postgraduate supervision. The results of this study are in accord with Severinsson (2012) who indicated that communication and interaction are crucial for quality postgraduate supervision. Characteristics that principally influenced postgraduate supervision were supervisory involvement and the supervisors' ability to communicate and interact which were confirmed in the current study.

\section{Limitations}

The research reported on in this paper represents preliminary findings of data collected as part of the development and testing of a psychometric stable measuring instrument. In addition non-random sampling was used to generate the sample influencing the external validity of the study. The sample is consequently not representative of the population and could not be generalized to said population. Despite this the results are valuable to identify trends and provide insight into postgraduate students' perception of postgraduate supervision. It is therefore recommended that the study be used as a basis for further investigation.

\section{Conclusion and Recommendations}

Internationally and nationally many endeavours are undertaken by higher education institutions to increase the effectiveness of postgraduate supervision underscoring for the most part the perspective of academic staff members. The study sought to determine the perception of postgraduate students by developing and testing a quantitative measuring instrument. When taking into consideration the viewpoints of different stakeholders the possibility of creating space for partnerships emerge.

In conclusion it is recommended that attention should be given to ensuring that there is a 'match' between the supervisory style of the supervisor and the personality of the student, and not only based on academic research foci. It is also recommended that higher education institution set clear guidelines and policies to govern the postgraduate supervisory relationship. Enhanced role description of both the supervisor and the student to minimize unrealistic expectations from students' would also add value. As well as clear instructions to students with regard to institutional processes and funding opportunities that are available. Since there appears to be an emotional need for motivation, support to mention but a few with regard to postgraduate students the establishment of a community of student groups to provide emotional support would also be advantageous. Reflective practices, for example chat rooms and reflective journals, should also be utilized.

\section{References}

Botha, N. (2010). Practices in postgraduate research supervision: from apprentice to scholar. Acta Academica Supplementum, 1, 57-74.

Bravo, G., Saint-Mleux, J., \& Dubois, M.F. (2007). Health Sciences graduate students' perceptions of the quality of their supervision: A measurement scale. The Canadian Journal of Higher Education, 37(2), 69-88.

Brew, A., \& Peseta, T. (2004). Changing postgraduate supervision practice: a programme to encourage learning through reflection and feedback. Innovations in Education and Teaching International, 41(1), 5-22.

De Beer, M., \& Mason, R.B. (2009). Using a blended approach to facilitate postgraduate supervision. Innovations in Education and Teaching International, 46(2), 213-226.

Franke, A., \& Arvidsson, B. (2011). Research supervisors' different ways of experiencing supervision of doctoral students. Studies in Higher Education, 36(1), 7-19.

Lee, A. (2007). Developing effective supervisors: Concepts of research supervision. South African Journal of Higher Education, 21(4), 680-693.

Lee, A., \& McKenzie, J. (2011). Evaluating doctoral supervision: Tensions in eliciting students' perspectives. Innovations in Education and Teaching International, 48(1), 69-78.

Manathunga, C. (2005). The development of research supervision: Turning the light on a private space. International Journal of Academic Development, 10(1), 17-30.

Maxwell, T.W., \& Smyth, R. (2010). Research supervision: the research management matrix. Higher Education, 59, 407-422.

Pearson, M., \& Brew, A. (2002). Research training and supervision development. Studies in Higher Education, 27(2), 135-150.

Petersen, E.B. (2007). Negotiating academicity: postgraduate research supervision as category boundary work. Studies in Higher Education, 32(4), 475-487.

Severinsson, E. (2012). Research supervision: supervisory style, research-related tasks, importance and quality - part 1. Journal of Nursing Management, 20, 215-223.

Sinclair, M. (2004). The pedagogy of 'good' PhD supervision: A national cross-disciplinary investigation of PhD supervision. Canberra: 
Department of Education, Science and Training.

South African Research and Innovation Management Association. (2013). Increasing throughput of postgraduate students in RSA, July. Wagner, C., Kawulich, B., \& Garner, M. (2012). Doing social research: A global context. Berkshire: McGraw-Hill Higher Education. Wagner, J. (2006). Visible materials, visualised theory and images of social research. Visual Studies, 21(1), 55-69. 